\title{
Morphometry of Suprascapular Notch in Northeast Brazilian Population
}

\begin{abstract}
Jalles Dantas de Lucena, ${ }^{1}$ Fábio Antônio Serra de Lima Júnior, ${ }^{2}$ Andressa Alves de Carvalho, ${ }^{2}$ Lucas de Andrade Alexandre, ${ }^{2}$ Tássia Santos de Melo, ${ }^{2}$ Maria Clara Motta Barbosa Valente, ${ }^{3}$ Francisco Orlando Rafael Freitas, ${ }^{4}$ Gilberto Santos Cerqueira, ${ }^{1}$ André de Sá Braga Oliveira²
\end{abstract}

\author{
${ }^{1}$ Federal University of Ceará - UFC, Fortaleza, CE, Brazil \\ universidade Federal da Paraíba, João Pessoa, PB, Brazil \\ 3Universidade Estadual de Ciências da Saúde de Alagoas - UNCISAL, Maceió, AL, Brazil \\ ${ }^{4}$ Faculdades Integradas de Patos - FIP, Patos, PB, Brazil
}

Disclose and conflicts of interest: none to be declared by all authors

\begin{abstract}
Introduction: the suprascapular notch (SSN) lies on the superior border of scapula, close to the root of coracoid process. The suprascapular nerve passes through the notch, below superior transverse scapular ligament. The objective of the present study was to analyze the main morphological aspects of SSN in scapulae of Northeast Brazil.

Material and Methods: a total of 97 adult unpaired scapulae of unknown age and sex were randomly selected. The shape of SSN was determined by direct inspection and the vertical and transverse diameters of the SSN were measured. The type of SSN was determined by using the classification of Natsis et al. (2007) and Iqbal et al. (2010). The results were recorded and statistically analyzed.

Results: in the studied scapulae, the SSN was revealed in $70.10 \%$, absent in $29.90 \%$ and none of scapulae has bony foramen. Considering Natsis et al., type II SSN was the most common finding on $62.88 \%$ scapulae, followed by type I SSN with $29.90 \%$ and type III with $7.22 \%$. Types IV and V were not found. According Iqbal et al., only 68 scapulae were macroscopically analyzed, $58.82 \%$ were J-shaped and $41.18 \%$ were U-shaped. There was not any V-shaped scapula found. The SSN had a longest transverse diameter (type II) in $62.88 \%$ and had a longest vertical diameter (type III) in $7.22 \%$.

Conclusion: knowledge of the anatomical variations of the SSN is useful for anatomists, orthopedic surgeons, radiologists and neurosurgeons for a better diagnosis and management of the entrapment syndrome.

Key words: Brazilian Scapula; Suprascapular Notch; Superior Transverse Scapular Ligament.
\end{abstract}

\section{Introduction}

Scapula is a triangular flat bone of the pectoral girdle that relies on the posterolateral chest wall between second and seventh ribs ${ }^{1}$. On its superior border, just medial to the root of coracoid process, we may find the suprascapular notch (SSN). This SSN may vary in depth and width, as well as be partial or completely closed by the superior transverse scapular ligament (STSL), forming the suprascapular foramen. This foramen transmits the suprascapular nerve, which supplies motor branches to the infraspinatus and supraspinatus muscles and sensory branches to the rotator cuff muscles, shoulder joint, acromioclavicular joint, coracohumeral ligament and coracoacromial ligament ${ }^{2}$.

The SSN shape and size are the main factor on the etiology of suprascapular nerve compression ${ }^{3,4}$. Suprascapular nerve neuropathy is a major issue for high performance athletes who practice high impact activities that repeatedly use shoulders joint. Volleyball players, baseball players, weightlifters and tennis players may reach a prevalence of $33 \%$ of suprascapular nerve entrapment ${ }^{5}$. Furthermore, 1 to $2 \%$ of shoulder pain is caused by this syndrome ${ }^{6}$. Suprascapular nerve entrapment syndrome is related to chronic and badly localized pain on posterolateral aspect of the shoulder, which can spread to the arm or the neck, to arm weakness, to abduction and extern rotation prejudice and to supraspinatus and infraspinatus muscles atrophy,

Previous studies analyzed variations on SSN shape. Rengachary et al..$^{9,10,11}$ classified the SSN into six types based on the shape of the notch and ossification of the STSL. Bayramoğlu et al..$^{12}$ modified the classification of Rengachary et al.9,10,11 and included only U-shaped and V-shaped notches, and the SSN with STSL ossification. More recently, Natsis et al. ${ }^{4}$ and Polguj et al. ${ }^{6}$ have established a new method of classification considering geometrical parameters of vertical (VD) and transverse (TD) diameters of SSN, the ossification of STSL and the presence of SSN with the foramen. Iqbal et al..$^{13}$ classified SSN according to U-, V- and J- shapes.

Reviewing the literature, there was only one brazilian morphometry study on the SSN, especially focusing 
on STSL ossification. Silva et al. ${ }^{30}$ found a greater prevalence of ossification on Rio de Janeiro's scapulae (30,76\%) than other nationalities, whose prevalence ranged from $1,5 \%$ to $6,5 \%$. Again, habits related to activities using shoulders joint may be related to the prevalence of ossification, as well as SSN format. Therefore, assuming diferences on brazilian STSL, it might be possible the SSN shape is also different on this population. Additionally, Agrawal et al. ${ }^{31}$ referred to ossifications of the coracoid process and epiphysis possibly being associated to different shapes of the SSN.

Considering clinical finds that might be related to suprascapular nerve entrapment ${ }^{14,15}$ and the absence of data on literature about SSN classification in Northeast Brazilian population, the present study aims to analyze the main morphological aspects of SSN in Northeast Brazil. The anatomical knowledge about shape and size of SSN has major importance for anatomists, radiologists and surgeons.

\section{Materials and Methods}

A total of 97 dried human scapulae (55 right and 42 left) were analyzed on Federal University of Ceará (UFC), State University of Health Sciences of Alagoas (UNCISAL) and Integrated Faculties of Patos (FIP) Anatomy Laboratories, all located in Northeast Brazil. Scapulae presenting bone pathologies or degradations on SSN were excluded. There was not gender, race or age identification on specimens.

Scapulae without SSN were registered and separated for posterior analysis. The ones with SSN were identified as U-shaped, V-shaped and J-shaped, according to Iqbal et al. ${ }^{13}$ classification system.

After morphological classification, VD and TD were measured and used to classify according to Natsis et al. ${ }^{4}$ classification system:

Type I - Absence of notch ou foramen;

Type II - Notch with TD bigger then VD;

Type III - Notch with VD bigger than TD;

Type IV - Presence of a foramen;

Type V - Presence of both a notch and a foramen.

The TD is defined as the maximum distance between the two borders of SSN and VD is the distance between the deepest point of SSN and the medium point of the imaginary line that unites the two superior borders of SSN (Figure 1). A transparent ruler was placed perpendicular to the borders of SSN, in order to help measuring VD. Measurement was realized using a digital vernier caliper with $0.01 \mathrm{~mm}$ precision (Figure 2).

The statistical analysis was performed on GraphPad Prism version 6.00 for Windows, California U.S.A. Shapiro-Wilk test was used to check whether the distribution was normal or abnormal. The statistical difference between both the suprascapular notch VD and TD measurements was examined using the Student t-test. Values of $\mathrm{p}<0.05$ were considered significant.
The descriptive analysis was used to present the other results.

The study was approved by the Cearás Federal University Ethics Committee (CAAE: 15006918.0.0000.5054)

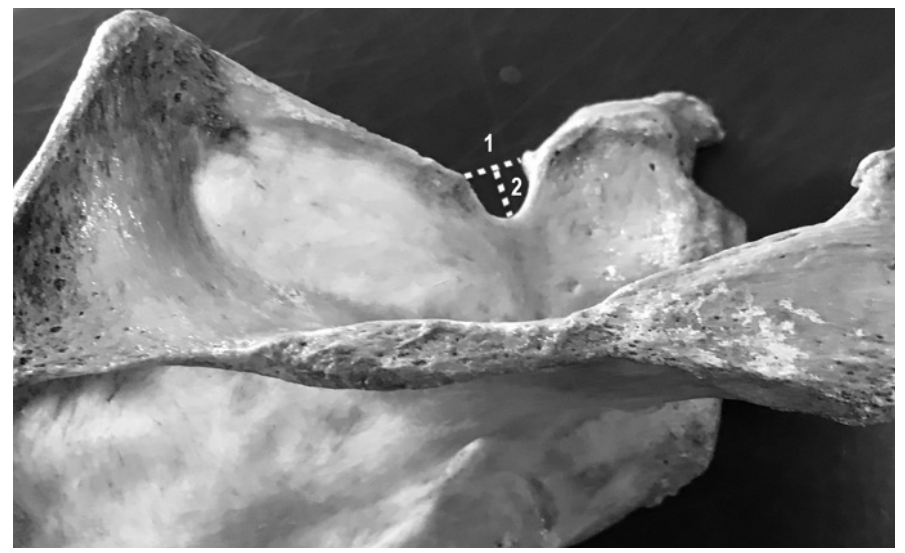

Figure 1. Dimensions of the suprascapular notch: 1 - Transverse diameter (TD); 2 - Vertical diameter (VD).

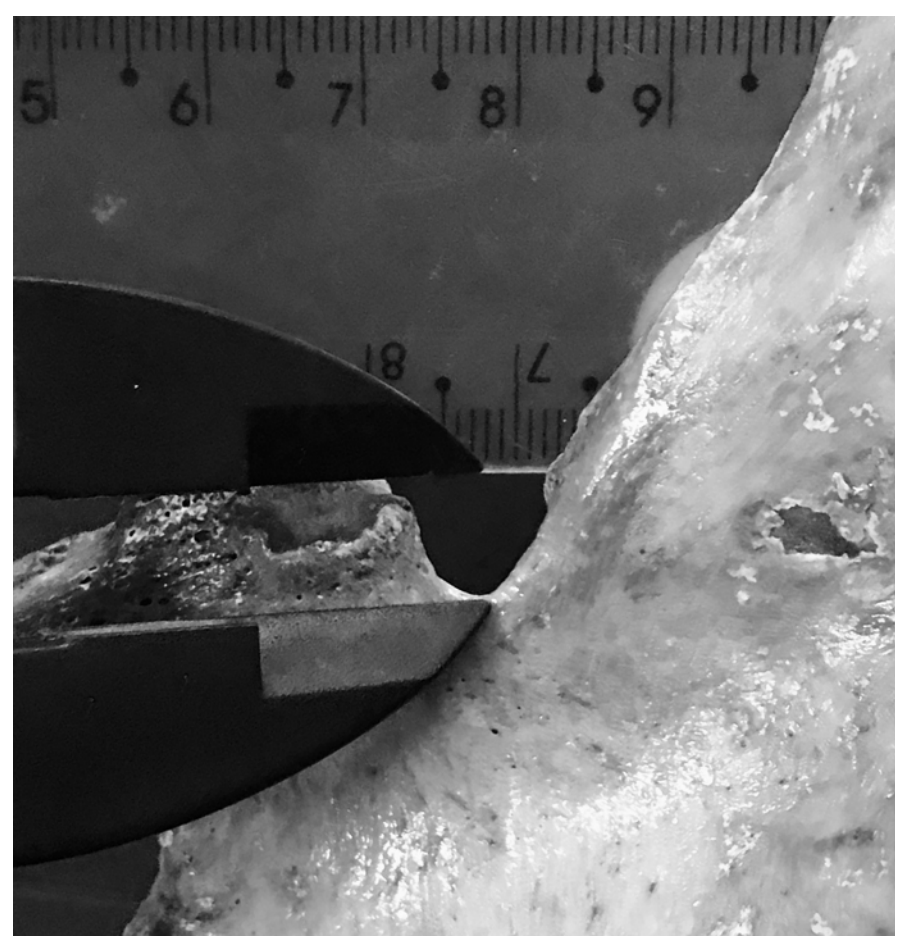

Figure 2. Using transparent ruler and digital caliper to measure the vertical diameter (VD) of the suprascapular notch (SSN).

\section{Results}

Ninety-seven dried human scapulae (55 right and 42 left) were analyzed in this study. Eight (8.24\%) scapulae had a discrete notch. None of scapulae had a present bony foramen (STSL was completely ossified).

Considering Natsis et al. ${ }^{4}$ classification system, type II SSN was the most common finding on $62.88 \%$ scapulae (Figure 3.A), followed by type I SSN with $29.90 \%$ and type III with $7.22 \%$ (Figure 3.B). Types IV and $\mathrm{V}$ were not found (Table 1). 


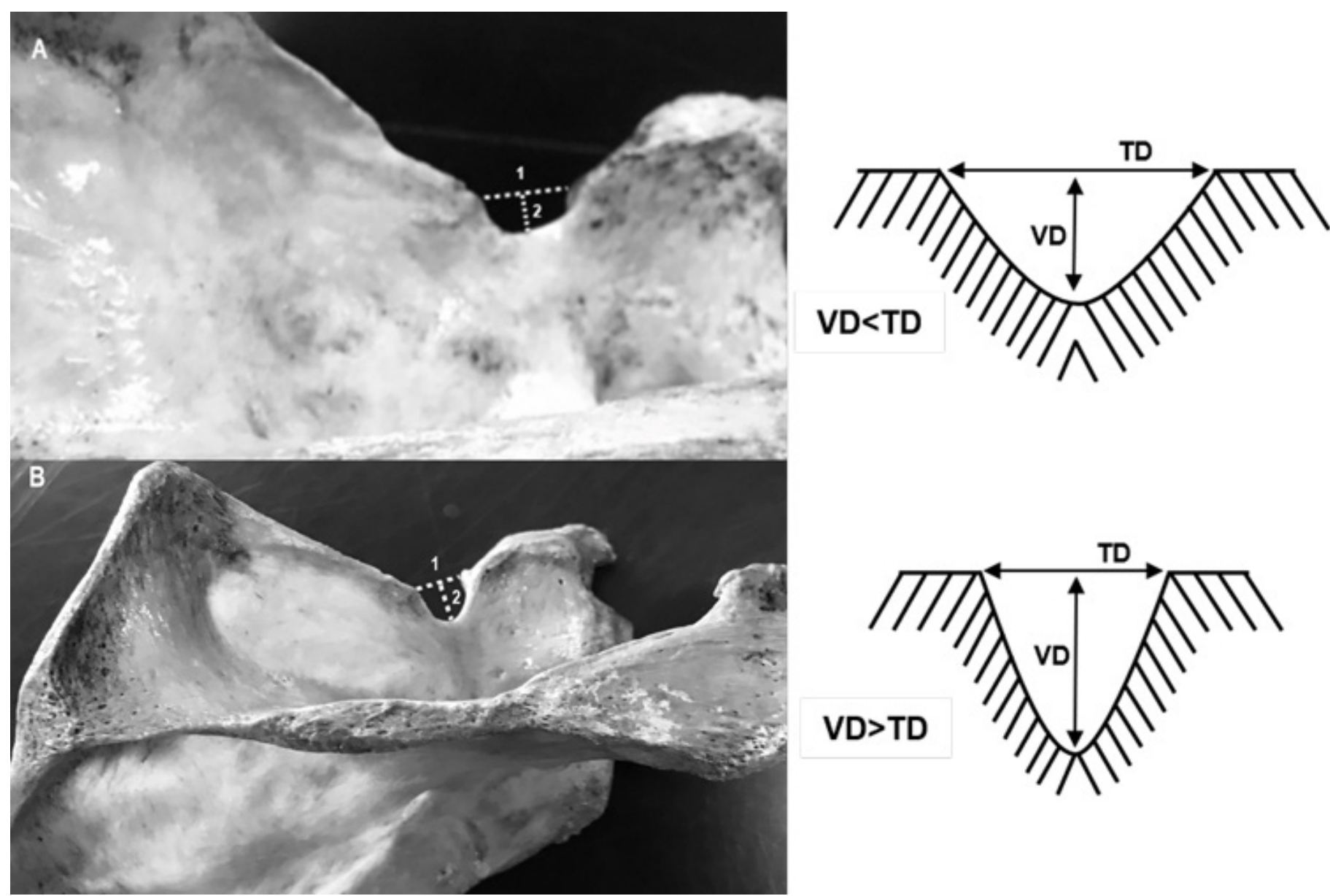

Figure 3. A- Scapulae with longer transverse diameter (Type II); B- Scapulae with longer vertical diameter (Type III). 1- Transverse diameter (TD); 2- Vertical diameter (VD).

Table 1. Frequency of various types of SSN according the classification given by Natsis et al. ${ }^{4}$.

\begin{tabular}{l|c|c|c}
\hline \multicolumn{1}{c|}{ Types of SSN } & Total & Right & Left \\
\hline Type I (SSN absent) & $29(29.90 \%)$ & $18(18.56 \%)$ & $11(11.34 \%)$ \\
\hline Type II (TD>VD) & $61(62.88 \%)$ & $34(35.04 \%)$ & $27(27.84 \%)$ \\
\hline Type III (VD>TD) & $7(7.22 \%)$ & $3(3.10 \%)$ & $4(4.12 \%)$ \\
\hline $\begin{array}{l}\text { Type IV (Foramen } \\
\text { present) }\end{array}$ & - & - & - \\
\hline $\begin{array}{l}\text { Type V (Presence of } \\
\text { SSN and foramen) }\end{array}$ & - & - & - \\
\hline Total & $97(100.0 \%)$ & $55(56.70 \%)$ & $42(43.30 \%)$ \\
\hline
\end{tabular}

Legend: SSN - suprascapular notch; VD- Vertical Diameter; TD - Transverse Diameter.

Measurement values of VD and TD are shown on Table 2. Comparing right and left values, no statistically significant difference found ( $p>0,05)$.

According to Iqbal et al. ${ }^{13}$ classification system, only 68 scapulae were macroscopically analyzed, since 29 specimens did not show SSN. Among those, 40 (58.82\%) were J-shaped and 28 (41.18\%) were U-shaped. There was not any V-shaped scapula found in our sample (Table 3).
Table 2. Measurements of different types of SSN according the classification given by Natsis et al. ${ }^{4}$.

\begin{tabular}{c|c|c|c|c}
\hline \multirow{2}{*}{$\begin{array}{c}\text { Types } \\
\text { of SSN }\end{array}$} & \multicolumn{2}{|c|}{$\begin{array}{c}\text { Vertical Diameter } \\
(\mathbf{m m})\end{array}$} & \multicolumn{2}{c}{$\begin{array}{c}\text { Transverse Diameter } \\
(\mathbf{m m})\end{array}$} \\
\cline { 2 - 5 } & Right & Left & Right & Left \\
\hline Type I & - & - & - & - \\
\hline Type II & $\begin{array}{c}4.94 \pm 2.44 \\
(2.54-10.22)\end{array}$ & $\begin{array}{c}3.94 \pm 2.06 \\
(1.08-7.83)\end{array}$ & $\begin{array}{c}8.23 \pm 2.92 \\
(3.65-13.86)\end{array}$ & $\begin{array}{c}7.93 \pm 2.52 \\
(3.73-12.74)\end{array}$ \\
\hline \multirow{2}{*}{ Type III } & $\begin{array}{c}10.12 \pm 2.10 \\
(8.07-12.27)\end{array}$ & $\begin{array}{c}7.83 \pm 1.28 \\
(6.45-9.02)\end{array}$ & $\begin{array}{c}8.37 \pm 2.07 \\
(6.04-10.03)\end{array}$ & $\begin{array}{c}7.00 \pm 1.68 \\
(5.09-8.74)\end{array}$ \\
\hline Type IV & - & - & - & - \\
\hline Type V & - & - & - & - \\
\hline
\end{tabular}

*Mean \pm SD. Legend: SSN - suprascapular notch; mm - millimeter.

Table 3. Frequency of SSN according the classification given by Iqbal et $a l^{13}$.

\begin{tabular}{l|c|c|c}
\hline \multirow{2}{*}{\multicolumn{1}{c}{ Types }} & \multicolumn{3}{|c}{ Frequency } \\
\cline { 2 - 4 } & Total & Right & Left \\
\hline Shape V & - & - & - \\
\hline Shape U & $28(41.18 \%)$ & $17(25.00 \%)$ & $11(16.18 \%)$ \\
\hline Shape J & $40(58.82 \%)$ & $20(29.42 \%)$ & $20(29.40 \%)$ \\
\hline Total & $68(100.0 \%)$ & $37(54.42 \%)$ & $31(45.58 \%)$ \\
\hline
\end{tabular}




\section{Discussion}

The SSN anatomy assessment is essential for diagnosis and treatment of scapular nerve entrapment. Examiningliterature, many studies are found describing $\mathrm{SSN}$, although few of them foreground qualitatively and quantitatively its anatomy. The present study was focused on measuring and classifying SSN based on its shape and dimensions.

Considering Natsis et al. ${ }^{4}$ classification, all studies collected on literature referenced Type II SSN as the most frequent, excepting Natsis et al. ${ }^{4}$ and Mahdy et al. ${ }^{16}$ which found the same frequency for both Type II and Type III. Globally, the data collected on data base searching (Table 4) analyzed 1492 scapulae, of which $135(9,12 \%)$ were classified as Type I, $804(53,89 \%)$ as Type II, $459(30,76 \%)$ as Type III, $69(4,62 \%)$ as Type IV and $24(1,61 \%)$ as Type V scapulae. At the same time, the present sample contained 29 (29,90\%) Type I, 61 (62,89\%) Type II, 7 (7,22\%) Type III and no scapulae of Type IV or Type V. Consequently, as well as the global statistics, Northeast Brazilian presented Type II as most frequent scapulae. However, it was found more Type I than Type III SSN on the sample, which differs from what is found worldwide.

The absence of Type IV and Type V scapulae doesn't seem as a surprise, since they have very low prevalence globally. Maybe, a bigger sample could find these types.

The absence of statistically significant difference between diameters on both sides may be either a near symmetry between sides or a reduced sample incapable to present a difference for now hidden. In a Chinese study which collected a major sample of 295 specimens, it was noticeable a statistical difference between sides, when analyzing TD and VD, both larger in the right scapulae ${ }^{17}$. However, an ultrasonographic morphometric study made in Ankara with 50 volunteers, as well as the present study, found no difference between SSN measures ${ }^{29}$.

Studied authors have classified SSN based on various parameters and gross examination of its shape. Iqbal et al. ${ }^{13}$ classified SSN into ' $U$ ', 'V', 'J' shapes based on gross examination. Soni et al. ${ }^{18}$ identified five types of SSN as ' $U$ ', ' $V$ ', ' $J$ ', indentation and absence of notch. The present study predominantly showed Iqbal type ' $\mathrm{J}$ ' shaped notches. The comparison between the present and previous studies based on shape are tabulated in Table 5.

The sum of different shapes may not be equal to sample size due to the present scapulae without SSN (Type I) or different parameters of classification. Globally, previous studies observed 1454 scapulae and classified 1117 (76,82\%) SSN, which 577 (51,66\%) were U-shaped, 177 (15,85\%) V-shaped and 363 (32,50\%) V-shaped SSN. The present study sample contained 97 scapulae, which had 29 absences of SSN, as well as 28 (28,87\%) U-shaped, 40 (58,82\%) J-shaped notches and none V-shaped notches. Therefore, the most frequent global notch was U-shaped, except for Nagaraj et $a .^{28}$ and Patra et $a l . .^{23}$. These both Indian studies had $\mathrm{J}$-shaped as most prevalent, as well as it was found on this sample, and are outliers on their country, since all Indian studies together showed $290(45,67 \%) \mathrm{U}$-shaped, 58 (9,13\%) V-shaped and 175 (27,56\%) J-shaped SSN. Thereby, it may represent an occasional finding or and ethnical difference, which can be elucidated by further bigger studies.

Table 4. Frequency of SSN types in various studies based on Natsis et al. ${ }^{4}$ classification.

\begin{tabular}{|c|c|c|c|c|c|c|c|}
\hline Author and year & Country & Sample (n) & Type I & Type II & Type III & Type IV & Type V \\
\hline Present study & Brazil & 97 & 29 & 61 & 7 & - & - \\
\hline Natsis et al. $(2007)^{4}$ & Germany & 423 & 35 & 177 & 177 & 31 & 3 \\
\hline Mahdy et al. (2013) & Egypt & 133 & 8 & 60 & 59 & 4 & 2 \\
\hline Wang et al. (2011) & China & 294 & 28 & 171 & 83 & 12 & - \\
\hline Soni et al. $(2012)^{18}$ & India & 100 & 5 & 72 & 20 & 3 & - \\
\hline Vandana et al. (2013) ${ }^{19}$ & India & 124 & 6 & 87 & 10 & 4 & 17 \\
\hline Shivaleela et al. $(2014)^{20}$ & India & 102 & 15 & 72 & 13 & 2 & 0 \\
\hline Sharma et al. (2015) ${ }^{21}$ & India & 100 & 20 & 39 & 34 & 5 & 2 \\
\hline Chhabra et al. $(2016)^{22}$ & India & 126 & 14 & 60 & 49 & 3 & - \\
\hline Patra et al. $(2016)^{23}$ & India & 90 & 5 & 66 & 14 & 5 & - \\
\hline
\end{tabular}


Table 5. Frequency of SSN types in various studies based on Iqbal et al.13 classification.

\begin{tabular}{|c|c|c|c|c|c|}
\hline Author and year & Country & Sample (n) & U-shaped & V-shaped & J-shaped \\
\hline Present study & Brazil & 97 & 28 & - & 40 \\
\hline Iqbal et al. $(2010)^{13}$ & Pakistan & 250 & 55 & 45 & 55 \\
\hline Duparc et al. $(2010)^{24}$ & France & 30 & 19 & 11 & - \\
\hline Soni et al. (2012)18 & India & 100 & 58 & 7 & 27 \\
\hline Vandana et al. (2013) ${ }^{19}$ & India & 134 & 47 & 7 & 46 \\
\hline Shivaleela et al. (2014) 20 & India & 110 & 47 & 8 & 29 \\
\hline Chhabra et al. (2016) & India & 126 & 58 & 31 & 20 \\
\hline Patra et al. (2016) ${ }^{23}$ & India & 110 & 35 & 10 & 43 \\
\hline Patel et al. $(2013)^{25}$ & India & 72 & 38 & 6 & 28 \\
\hline Sangam et al. $(2013)^{26}$ & India & 104 & 72 & 28 & - \\
\hline Sutaria et al. $(2013)^{27}$ & India & 314 & 120 & 22 & 70 \\
\hline Nagaraj et al. (2014)28 & India & 104 & 28 & 2 & 45 \\
\hline
\end{tabular}

\section{Conclusion}

Since the suprascapular nerve has an intimate relation to the SSN, studying its variations is essential to understand suprascapular nerve entrapment syndrome. The reduced size of SSN and ossification of STSL may minimize the space available to the nerve leading to the syndrome, which results on pain during the begging of shoulder abduction and on weakness and wasting of supraspinatus and infraspinatus muscles. This study is useful for anatomists, orthopedic surgeons, radiologists and neurosurgeons for a better diagnosis and management of the entrapment syndrome. J-shaped and Type II SSN were the most predominant on Brazilian's Northeast sample and anatomical variations should be kept in mind by surgeons before interventions.

\section{References}

1 Moore KL, Dalley II AF, Agur AMR, Baltimore MD. Clinically Oriented Anatomy. 7nd edition. Philadelphia: Lippincott Williams \& Wilkins; 2014:807-808

2 Standring S. Suprascapular notch. In: Gray's Anatomy. The anatomical basis of clinical practise.40nd edition. London: Churchill Livingstone; 2008:794-795

3 Dunkelgrun M, lesaka K, Park SS, Kummer FJ, Zuckerman JD. Interobserver reliability and intraobserver reproducibility in suprascapular notch typing. Bull Hosp Jt Dis 2003;61(3-4):118-122

4 Natsis K, Totlis T, Tsikaras P, Appell HJ, Skandalakis P, Koebke

J. Proposal for classification of the suprascapular notch: a study on 423 dried scapulas. Clin Anat 2007;20(2):135-139. Doi: 10.1002/ ca.20318

5 Holzgraefe M, Kukowski B, Eggert S. Prevalence of latent and manifest suprascapular neuropathy in high-performance volleyball players. Br J Sports Med 1994;28(3):177-179. Doi: 10.1136/ bjsm.28.3.177

6 Polguj M, Sibiṅski M, Grzegorzewski A, Grzelak P, Majos A, Topol M. Variation in morphology of suprascapular notch as a factor of suprascapular nerve entrapment. Int Orthop 2013;37(11):2185-2192. Doi: 10.1007/s00264-013-2005-3

7 Gosk J, Urban M, Rutowski R. Entrapment of the suprascapular nerve: anatomy, etiology, diagnosis, treatment. Ortop Traumatol Rehabil 2007;9(1):68-74. PMID: 17514177
8 Boykin RE, Friedman DJ, Zimmer ZR, Oaklander AL, Higgins LD, Warner JJ. Suprascapular neuropathy in a shoulder referral practice. J Shoulder Elbow Surg 2011;20(6):983-988. Doi: 10.1016/j. jse.2010.10.039

9 Rengachary SS, Neff JP, Singer PA, Brackett CE. Suprascapular entrapment neuropathy: a clinical, anatomical and comparative study. Part 1: clinical study. Neurosurgery 1979;5(4):441-446. PMID: 534047

10 Rengachary SS, Burr D, Lucas S, Hassanein KM, Mohn MP, Matzke H. Suprascapular entrapment neuropathy: a clinical, anatomical and comparative study. Part 2: anatomical study. Neurosurgery 1979;5(4):447-451. PMID: 534048

11 Rengachary SS, Burr D, Lucas S, Brackett CE. Suprascapular entrapment neuropathy: a clinical, anatomical, and comparative study. Part 3: comparative study. Neurosurgery. 1979;5(4):452-455. PMID: 534049

12 Bayramoğlu A, Demiryürek D, Tüccar E, et al. Variations in anatomy at the suprascapular notch possibly causing suprascapular nerve entrapment: an anatomical study. Knee Surg Sports Traumatol Arthrosc. 2003;11(6):393-398. Doi: 10.1007/s00167-003-0378-3 13 Iqbal K, Iqbal R, Khan SG. Anatomical variations in shape of suprascapular notch of scapula. J Morphol Sci. 2010;27(1):1-2 14 Tubbs RS, Nechtman C, D'Antoni AV, et al. Ossification of the suprascapular ligament: A risk factor for suprascapular nerve 
compression?. Int J Shoulder Surg 2013;7(1):19-22. Doi: 10.4103/09736042.109882

15 Albino P, Carbone S, Candela V, Arceri V, Vestri AR, Gumina S. Morphometry of the suprascapular notch: correlation with scapular dimensions and clinical relevance. BMC Musculoskelet Disord 2013;14(172):1-10. Doi: 10.1186/1471-2474-14-172

16 Mahdy AA, Shehab AA. Morphometric Variations of the Suprascapular Notch as a Potential Cause of Neuropathy: Anatomical Study. J Am Sci 2013;9(3):189-197

17 Wang HJ, Chen C, Wu LP, Pan CQ, Zhang WJ, Li YK. Variable morphology of the suprascapular notch: an investigation and quantitative measurements in Chinese population. Clin Anat 2011;24(1):47-55. Doi: 10.1002/ca.21061

18 Soni G, Malik VS, Shukla L, Chabbra S, Gaur N. Morphometric Analysis of the Suprascapular Notch. Internet J Biol Anthropol 2012;5(1). Doi: 10.5580/2b19

19 Vandana R, Patil S. Morphometric study of suprascapular notch. Natl J Clin Anat 2013;2(3):140-144

20 Shivaleela C, Archana BJ, Kumar GV, Swetha R, Lakshmiprabha S. Morphometric analysis of suprascapular notch in Human Adult scapulae with clinical Relevance. Res J Pharm Biol Chem Sci 2014;5(6):741-747

21 Sharma R, Sharma R, Singla RK, Kullar JS, Sharma T. Suprascapular Notch: a Morphometric and Morphologic Study in North Indian Population. Int J Anat Res 2015;3(3):1306-1311. Doi: 10.16965/ijar.2015.217

22 Chhabra N, Prakash S, Ahuja M. Morphometry and Morphology of Supra Scapular Notch: It'S Importance in Suprascapular Nerve Entrapment. Int J Anat Res 2016;4(3.1):2536-2541. Doi: 10.16965/ ijar.2016.267

23 Patra A, Kalyan GS, Kaur H, Chhabra U, Kaushal S, Upasana.
Variations in shape and dimension of suprascapular notch in dried human scapulae: An osteological study with its clinical implications. J Anat Soc India 2016;65:S51. Doi: 10.1016/j.jasi.2016.08.167 24 Duparc F, Coquerel D, Ozeel J, Noyon M, Gerometta A, Michot C. Anatomical basis of the suprascapular nerve entrapment, and clinical relevance of the supraspinatus fascia. Surg Radiol Anat 2010;32(3):277-284. Doi: 10.1007/s00276-010-0631-7

25 Patel P, Patel SV, Patel SM, Jotania B, Chavda S, Patel D. Study of variations in the shape of the suprascapular notch in Dried Human Scapula. Int J Biol Med Res 2013;4(2):3162-3164

26 Sangam MR, Sarada Devi SS, Krupadanam K, Anasuya K. A study on the morphology of the suprascapular notch and its distance from the glenoid cavity. J Clin Diagnostic Res 2013;7(2):189-192. Doi: 10.7860/JCDR/2013/4838.2723

27 Sutaria LK, Nayak TV, Patel SV, Jadav HR, Pensi CA. Morphology and morphometric analysis of suprascapular notch. Int J Biomed Adv Res 2013;4(1):35-39. Doi: 10.7439/ijbar.v4i1.891

28 Nagaraj S, Krishnaiah M, Kumar MP, Sherke AR. Study of Morphological Variations of Suprascapular Notch. IOSR J Dent Med Sci 2014;13(6):121-123. Doi: 10.9790/0853-1361121123

29 Yücesoy C, Akkaya T, Ozel O, et al. Ultrasonographic evaluation and morphometric measurements of the suprascapular notch. Surg Radiol Anat 2009;31(6):409-414. Doi: 10.1007/s00276-0080458-7

30 Silva JG, Abidu-Figueiredo M, Fernandes RMP, et al. High incidence of complete ossification of the superior transverse scapular ligament in Brazilians and its clinical implications. Int J Morphol 2007;25(4):855-859.

31. Agrawal D, Singh B, Dixt SG, et al. Morphometry and variations of the human suprascapular notch. Morphologie 2015; 99(327):132-140. Doi: 10.1016/j. morpho.2015.04.002
Received: January 11, 2021

Accepted: April 4, 2021
Corresponding author

Jalles Dantas de Lucena

E-mail: jallesdantas@gmail.com 